\title{
Neuropathic pain: current definition and review of drug treatment
}

\section{Bridin P Murnion \\ Senior clinical lecturer University of Sydney \\ Senior staff specialist Drug Health Services Concord Repatriation General Hospital \\ Sydney}

\section{Keywords}

anticonvulsants, antidepressants, cannabinoids, neuropathic pain, opioids

Aust Prescr 2018;41:60-3

https://doi.org/10.18773/ austprescr.2018.022

\section{SUMMARY}

Neuropathic pain is relatively common and often poorly treated.

Management options include tricyclic antidepressants or serotonin and noradrenaline reuptake inhibitors in the first instance, followed by pregabalin or gabapentin.

Tramadol or topical lidocaine (lignocaine) could be considered as second line. Stronger opioids have been relegated to third line.

It is important to remember that opioids and gabapentinoids have abuse potential.

Fibromyalgia and chronic low back pain without radiculopathy do not meet the current criteria for the definition of neuropathic pain.

\section{Introduction}

Neuropathic pain is associated with impaired quality of life, and is often poorly managed. Around $7-8 \%$ of adults have pain with neuropathic characteristics. A quarter of people with diabetes and $35 \%$ of people with HIV have neuropathic pain.'

The management of neuropathic pain can be challenging and, as with all pain, should be approached with a biopsychosocial framework. There are several options for drug treatment as part of an overall approach to improve patients' quality of life and function. ${ }^{2}$

International guidelines have clarified the definition of neuropathic pain and updated their recommendations for drug treatment based on evidence from a systematic review and meta-analysis. ${ }^{3,4}$ Being aware of these changes is important in the clinical assessment and treatment.

\section{A new definition for neuropathic pain}

Neuropathic pain is now defined by the International Association for the Study of Pain (IASP) as 'pain caused by a lesion or disease of the somatosensory nervous system? ${ }^{3}$ This replaces the older definition of 'pain initiated or caused by a primary lesion, dysfunction or transitory perturbation of the peripheral or central nervous system'.

The definition was reviewed and updated because the term dysfunction in the old definition was thought to be over-inclusive and did not reflect the pathophysiology. Additionally, neuropathic pain is not one disease entity but a number of diseases or lesions with a cluster of symptoms and signs, where understanding of pathophysiology is evolving. ${ }^{5}$
Proponents of the change believe it has greater scientific rigour. It removes confusion around pain arising as a result of disease within the nervous system but outside the somatosensory system, for example pain from muscle spasticity. It now excludes syndromes where pathophysiology is unclear, such as fibromyalgia or complex regional pain syndrome, which is controversial and has been perceived by some to be overly restrictive. ${ }^{6}$

\section{Primary disease management}

The primary disease management of neuropathic pain needs to consider the individual as a whole. For instance, in patients with diabetic neuropathy, erratic glycaemic control worsens symptoms and improving glycaemic control may reduce progression of neuropathy. However, there is increased mortality with intensive insulin regimens in patients with established diabetic neuropathy compared to patients without neuropathy. ${ }^{7}$ HIV-associated neuropathy presents an even more complex picture - starting antiretrovirals may initially improve symptoms although nerve damage may progress. Some antiretrovirals can cause neuropathy, and neurotoxicity may be a feature of concomitant medicines such as isoniazid for tuberculosis. ${ }^{8,9}$

\section{Drugs for neuropathic pain}

The IASP's Neuropathic Pain Special Interest Group (NeuPSIG) has recently undertaken a systematic review of medicines for neuropathic pain (Table). ${ }^{4}$ Fibromyalgia, atypical facial pain, complex regional pain syndrome and chronic low back pain without radiculopathy were not included in the review as they do not meet the current criteria for the definition of neuropathic pain. 
The review included tricyclic antidepressants, serotonin and noradrenaline reuptake inhibitors (SNRIs), antiepileptic drugs, opioids, topical lidocaine (lignocaine), capsaicin high-concentration patches and oromucosal cannabinoids. A number of overarching themes were identified:

- most studies were conducted in diabetic neuropathy or postherpetic neuralgia

- publication bias accounted for approximately $10 \%$ of the treatment effect

- $\quad$ placebo effect was large

- drug effects were modest ${ }^{4}$

- data did not identify that one particular drug or drug class was superior in any particular neuropathic pain syndrome

- the majority of studies were for 12 weeks or less

- data were limited to non-cancer pain in adults.

\section{Antidepressants}

Tricyclic antidepressants and SNRIs were effective in reducing pain. Amitriptyline was the most studied tricyclic antidepressant (daily doses 25-150 mg) and did not show a dose-response effect. Seven of nine studies with duloxetine $20-120 \mathrm{mg}$ were positive, while two of four studies identified efficacy with venlafaxine 150-225 mg daily. The negative venlafaxine studies were at lower doses.

\section{Antiepileptics}

Most trials with pregabalin (18/25) showed improvement in neuropathic pain, and the effect was greater with larger doses. Pregabalin in HIV neuropathy was no better than placebo. However, the placebo was very effective. Gabapentin was also found to be effective, although no dose response was identified. The number needed to harm was 13.9 for pregabalin and 25.6 for gabapentin. Other antiepileptic drugs had minimal evidence of efficacy, and topiramate, carbamazepine and oxcarbazepine had a poor safety profile.

\section{Tramadol, tapentadol and opioids}

Tramadol consistently showed efficacy, while tapentadol had very limited supporting data. With morphine or oxycodone, 10 of 13 trials showed benefit, with no benefit in increasing the dose beyond $180 \mathrm{mg}$ daily oral morphine equivalents.

\section{Topical treatments}

There were some limited data suggesting the efficacy of lidocaine (lignocaine) 5\% patches, with good safety and tolerability. Although registered, this product is not available on the Pharmaceutical Benefits Scheme (PBS) ${ }^{10}$ so may be prohibitively expensive for patients.

\section{Table Drug treatment for neuropathic pain - updated recommendations from the International Association for the Study of Pain}

\begin{tabular}{ll}
\hline Recommendation & Drugs \\
\hline First-line & SNRI - duloxetine, venlafaxine \\
\cline { 2 - 2 } & Tricyclic antidepressants \\
\hline Second-line & Cabapentin, pregabalin \\
\hline & Lidocaine (lignocaine) patches \\
\cline { 2 - 2 } & Tramadol \\
\hline Third-line & Strong opioids \\
\hline
\end{tabular}

SNRI serotonin noradrenaline reuptake inhibitors

Adapted from reference 4

For postherpetic neuralgia and HIV neuropathy, a high-concentration (8\%) capsaicin patch demonstrated efficacy over a low-dose $(0.04 \%)$ patch. Unfortunately the high-dose patch is not available in Australia.

\section{Oromucosal cannabinoids}

The meta-analysis identified mostly negative data for a fixed-dose combination of cannabidiol and 9-tetrahydrocannabinol (nabiximols) in reducing pain in multiple sclerosis. ${ }^{4} \mathrm{~A}$ statement by the Faculty of Pain Medicine of the Australian and New Zealand College of Anaesthetists on medicinal cannabis identifies no role for the use of cannabinoids in neuropathic pain, but notes pain and spasticity related to multiple sclerosis may be an exception."

\section{Trigeminal neuralgia}

Trigeminal neuralgia is the only condition in which a specific drug class has shown superior efficacy. Carbamazepine and oxcarbazepine are first line for pharmacological pain management. ${ }^{12}$

It is currently recommended that Asian people of non-Japanese origin are tested for the HLA-B*1502 allele as this confers an increased risk of cutaneous drug reactions with carbamazepine. ${ }^{13}$

\section{Interventional modalities}

Local nerve blocks, spinal or epidural medicines, and neuro-ablative, neuromodulatory and neurosurgical procedures are also used for neuropathic pain. ${ }^{14}$ 


\section{Updated recommendations for treatment}

As a result of the meta-analysis, NeuPSIG has updated its recommendations for the treatment of non-cancer associated neuropathic pain in adults. With the exception of trigeminal neuralgia, there were no data identifying that any particular drug was superior to another in any particular disease state. ${ }^{4}$

The guidelines recommend tricyclic antidepressants, gabapentin or pregabalin, and the SNRIs venlafaxine or duloxetine as first line. ${ }^{4}$

Second-line treatments include tramadol. Topical lidocaine (lignocaine) or high-concentration capsaicin may be considered for neuropathic pain when there is a presumed local generator. ${ }^{4}$

The consensus is that opioids can no longer be recommended as first-line treatment, and there is general agreement that they should only be considered as third line, with appropriate monitoring for safety and efficacy. ${ }^{4}$ It is increasingly recognised that the harms of opioids, in particular addiction, cannot be adequately identified in short-term studies. Also, these short-term studies could not identify if any benefit persists or is lost as tolerance develops.

\section{A pragmatic approach to drug therapy}

Choose a tricyclic antidepressant or SNRI with consideration of the patient's comorbidities, potential drug interactions and adverse effects, and consider pregabalin or gabapentin next before tramadol. There is a paucity of guidance on duration of treatment. Again, a pragmatic approach may be to try a therapy for 12 weeks as this is the maximum duration of most of the trials. Monitor for efficacy (using multidimensional tools for pain intensity, quality of life and patient function) and safety, and stop if the treatment is not working.

The PBS listing for pregabalin in neuropathic pain is that 'the condition must be refractory to treatment with other drugs'. Cost of treatment is significant. In 2016-17, more than 3.5 million PBS scripts for pregabalin were issued at a cost of over $\$ 190$ million. ${ }^{15}$ Gabapentinoids have neurocognitive adverse effects, can cause weight gain and are associated with an increased risk of falls. They are anxiolytic, and there is emerging evidence of significant pregabalin abuse. ${ }^{16}$

Any consideration of psychotropic drugs including gabapentinoids or opioids (tramadol or stronger opioids) should involve:

- assessing the risk of abuse, including history of psychiatric, personality or substance use disorder

- ongoing monitoring for development of abuse

- multidimensional assessment of efficacy.

A plan to stop therapy should be discussed with the patient before treatment starts, and daily opioid doses should not exceed $60 \mathrm{mg}$ oral morphine equivalents without specialist review. ${ }^{17}$

\section{Conclusion}

A well-conducted meta-analysis reviewing drug treatment of neuropathic pain provides clear recommendations. Tricyclic antidepressants and SNRIs should be trialled first. If they are ineffective, consider a trial of a gabapentinoid then tramadol. This should be accompanied by multidimensional assessment of efficacy, review for harms associated with treatment and a plan for stopping treatment if there is no benefit. $<$

Conflict of interest: none declared

\section{REFERENCES}

1. International Association for the Study of Pain. Epidemiology of neuropathic pain: how common is neuropathic pain, and what is its impact? Washington: IASP; 2014. https://www.iasp-pain.org/Advocacy/Content. aspx?ItemNumber=3934 [cited 2018 May 1]

2. Pain Management Network [Internet]. Sydney: Agency for Clinical Innovation; 2018 www.aci.health.nsw.gov.au/chronicpain [cited 2018 May 1]

3. International Association for the Study of Pain. IASP Taxonomy. Pain terms. Neuropathic pain. Updated 2017 Dec 14. www.iasp-pain.org/Taxonomy\#Neuropathicpain [cited 2018 May 1]

4. Finnerup NB, Attal N, Haroutounian S, McNicol E, Baron R, Dworkin $\mathrm{RH}$, et al. Pharmacotherapy for neuropathic pain in adults: a systematic review and meta-analysis. Lancet Neurol 2015;14:162-73. https://doi.org/10.1016/S1474-4422(14)70251-0

5. Jensen TS, Baron R, Haanpää M, Kalso E, Loeser JD, Rice AS, et al. A new definition of neuropathic pain. Pain 2011;152:2204-5. https://doi.org/10.1016/j.pain.2011.06.017

6. Oaklander AL, Wilson PR, Moskovitz PA, Manning DC Lubenow T, Levine JD, et al. Response to "A new definition of neuropathic pain”. Pain 2012;153:934-5. https://doi.org/ 10.1016/j.pain.2012.01.012
7. Javed S, Alam U, Malik RA. Treating diabetic neuropathy: present strategies and emerging solutions. Rev Diabet Stud 2015;12:63-83. https://doi.org/10.1900/RDS.2015.12.63

8. Centner CM, Little F, Van Der Watt JJ, Vermaak JR, Dave JA, Levitt NS, et al. Evolution of sensory neuropathy after initiation of antiretroviral therapy. Muscle Nerve 2018;57:371-9. https://doi.org/10.1002/mus.25710

9. Centner CM, Bateman KJ, Heckmann JM. Manifestations of HIV infection in the peripheral nervous system. Lancet Neurol 2013;12:295-309. https://doi.org/10.1016/ S1474-4422(13)70002-4

10. Pharmaceutical Benefits Scheme. PBAC Public Summary Documents - March 2015. Lignocaine; 5\% patch: dermal, 30; Versatis. www.pbs.gov.au/info/industry/listing/elements/ pbac-meetings/psd/pbac-public-summary-documentsmarch-2015 [cited 2018 May 1]

11. Faculty of Pain Medicine, Australian and New Zealand College of Anaesthetists. Statement on "medicinal cannabis" with particular reference to its use in the management of patients with chronic non-cancer pain. PM10. Melbourne: ANZCA; 2015. http://fpm.anzca.edu.au/resources/ professional-documents [cited 2018 May 1] 
12. Cruccu G, Gronseth G, Alksne J, Argoff C, Brainin M, Burchiel K, et al.; American Academy of Neurology Society; European Federation of Neurological Society. AAN-EFNS guidelines on trigeminal neuralgia management. Eur J Neurol 2008:15:1013-28. https://doi.org/10.1111/ j.1468-1331.2008.02185.x

13. eTG complete [Internet]. Neurology. Trigeminal neuralgia and other cranial neuralgias. www.tg.org.au [cited 2018 May 1]

14. Dworkin RH, O'Connor AB, Kent J, Mackey SC, Raja SN, Stacey BR, et al. Interventional management of neuropathic pain: NeuPSIG recommendations. Pain 2013;154:2249-61. https://doi.org/10.1016/j.pain.2013.06.004
15. Pharmaceutical Benefits Scheme. Expenditure and prescriptions twelve months to 30 June 2017. Canberra: Commonwealth of Australia; 2017. http://www.pbs.gov.au/ info/statistics/expenditure-prescriptions-twelve-months-to30-june-2017 [cited 2018 May 1]

16. Schifano F. Misuse and abuse of pregabalin and gabapentin: cause for concern? CNS Drugs 2014;28:491-6 https://doi.org/10.1007/s40263-014-0164-4

17. Faculty of Pain Medicine, Australian and New Zealand College of Anaesthetists. Recommendations regarding the use of opioid analgesics in patients with chronic non-cancer pain. PM01. Melbourne: ANZCA; 2015. http://fpm.anzca.edu. au/resources/professional-documents [cited 2018 May 1] 